\title{
POLÍTICAS DE FORMAÇÃO DOCENTE À LUZ DO PLANO NACIONAL DE EDUCAÇÃO: ENTRE CONQUISTAS E DESAFIOS
}

\author{
Camila de Fátima Soares dos Santos ${ }^{1}$, Edite Maria Sudbrack ${ }^{2}$ \\ ${ }^{1}$ Mestre em Educação pela Universidade Regional Integrada do Alto Uruguai e das Missões - URI/Campus de Frederico \\ Westphalen. Docente do Curso de Pedagogia na Universidade Federal da Fronteira Sul - UFSS/Campus de Chapecó. E- \\ mail: camilafss13@gmail.com \\ ${ }^{2}$ Doutora em Educação Universidade Federal do Rio Grande do Sul - UFRGS. Docente do Mestrado em Educação da \\ Universidade Regional Integrada do Alto Uruguai e das Missões - URI/Campus de Frederico Westphalen. \\ sudbrack@uri.edu.br
}

\section{RESUMO}

Esse artigo emerge de uma pesquisa que tem por objetivo refletir e compreender os limites e as contribuições do Plano Nacional de Educação 2014-2024, no processo de produção das políticas de formação docente. A pesquisa é de natureza qualitativa, com enfoque bibliográfico e documental. Apresenta análise de uma política educacional de planejamento: Plano Nacional de Educação (2014-2024) e atos legais sancionados após sua promulgação, a Resolução no 2, de 1ㅇ de julho de 2015 e o Decreto no 8.752 , de 9 de maio de 2016; por isso, enquanto método de análise optamos pela análise de conteúdo proposta por Bardin (1977). O PNE vislumbrou novos caminhos, alimentando a esperança para efetivar uma política de formação, com vistas à uma educação pública de qualidade. A análise dos documentos possibilitou conhecer os direcionamentos das políticas de formação docente, ampliando o debate e a compreensão das conquistas e desafios que se apresentam em relação ao contexto de crise política e econômica atual.

Palavras-chave: Políticas educacionais. Plano Nacional de Educação. Formação docente.

\section{POLICIES OF FORMATION TEACHER IN THE LIGHT OF THE NATIONAL EDUCATION PLAN: BETWEEN ACHIEVEMENTS AND CHALLENGES}

\begin{abstract}
This article emerges from a research that aims to reflect and understand the limits and contributions of the National Education Plan 2014-2024, in the process of producing teacher education policies. The research is qualitative in nature, with bibliographical and documentary focus. It presents an analysis of an educational policy for planning: National Education Plan (2014-2024) and legal acts sanctioned after its promulgation, Resolution 2 of July 1, 2015 and Decree 8,752 of May 9 of 2016; so as a method of analysis we opted for the content analysis proposed by Bardin (1977). The PNE envisaged new paths, fueling hope for the implementation of a training policy, aiming at a quality public education. The analysis of the documents made it possible to know the directives of teacher education policies, broadening the debate and understanding of the achievements and challenges that are presented in relation to the current political and economic crisis context.
\end{abstract}

Keywords: Educational policies. National Education Plan. Formation teacher.

\section{PARA INICIAR O DEBATE}

O campo das políticas públicas caracteriza-se como uma arena de disputa de interesses, embates e resistências, que constituem concepções distintas sobre determinado assunto. Resultam, essencialmente, da atividade política que visa ao atendimento dos direitos dos cidadãos, de um processo permeado por decisão e participação da sociedade civil, em que se definem meios, agentes e fins para atingir os objetivos acordados. (DIAS; MATOS, 2012).

No tocante à educação, as políticas educacionais, as quais fazem parte das políticas sociais, revelam-se pela sua complexidade. Em nosso país, várias reformas educacionais foram empreendidas, principalmente, a partir da década 
de 1990, em resposta à globalização e o modelo neoliberal de Estado.

Nesse sentido é imperativo situar as políticas educacionais nacionais, notadamente, aquelas que configuram a profissionalização docente e que abrangem a formação e valorização desses profissionais, no contexto das mudanças globais, sejam econômicas, políticas ou sociais. Uma das justificativas, dentre tantas, para as reformas no campo educacional está embasada no discurso da qualidade e da necessidade de superar a crise nos índices, sobretudo, daqueles que se referem ao desempenho dos alunos perante os rankings internacionais.

Destarte, o tema desse artigo situa-se no campo das políticas educacionais de formação docente à luz do PNE. Portanto, buscamos refletir e compreender os limites e as contribuições do Plano Nacional de Educação 2014-2024, no processo de produção das políticas de formação docente. O caminho metodológico dessa pesquisa teve um enfoque qualitativo, com pesquisa bibliográfica e documental e enquanto método de análise optamos pela análise de conteúdo (BARDIN, 1977). Inicialmente, destacamos as políticas de formação docente no contexto do PNE 2014-2024; em seguida, trazemos para o debate as análises das metas que abordam a formação docente, bem como da Resolução CNE/CP no 02/2015 e do Decreto no 8.752 , numa perspectiva de compreender qual a direção que essas políticas assumem após a publicação desses documentos. Por fim, algumas considerações à guisa de conclusão.

\section{POLÍTICAS DE FORMAÇÃO NO CONTEXTO DO PNE 2014-2024}

Partindo do pressuposto de que as políticas públicas são entendidas também como o Estado em ação, compreendendo que é a materialização da presença estatal no contexto social, podemos dizer que o Estado traduzido em políticas, representa as instituições e suas diferentes formas de intervir na sociedade. Resta lembrar que, nesse espaço de atuação do Estado, existem forças contraditórias, em disputa pela hegemonia de poder em relação ao jogo político.

Nesse campo, encontra-se, também, a educação, a qual é situada, por vezes, como mola propulsora do desenvolvimento social. A disputa pelos rumos da educação brasileira se dá nos marcos institucionais da economia capitalista e da luta de classes, marcados por interesses antagônicos dos mais variados segmentos e, materializados em leis, decretos, resoluções que nunca assumem neutralidade, pois são resultados dessa confrontação política, de antagonismos que implicam no atendimento de alguns interesses e de abandono de outros.

Nessa arena, faz-se presente a lógica da economia capitalista, balizando as decisões e caminhos a serem seguidos.

No contexto da reforma do Estado, as décadas de 80 e 90 marcam a inserção dos países da América Latina na ordem neoliberal ${ }^{1}$. As políticas neoliberais foram amplamente difundidas na América Latina a partir da década de 1980. No Brasil, sua admissão foi nos anos de 1990, com o presidente Fernando Collor de Mello. Segundo Shiroma, Moraes e Evangelista (2002, p. 55), "com Collor deflagrou-se o processo de ajuste da economia brasileira às exigências da reestruturação global da economia".

De acordo com Malanchen e Vieira (2006, p. 4)

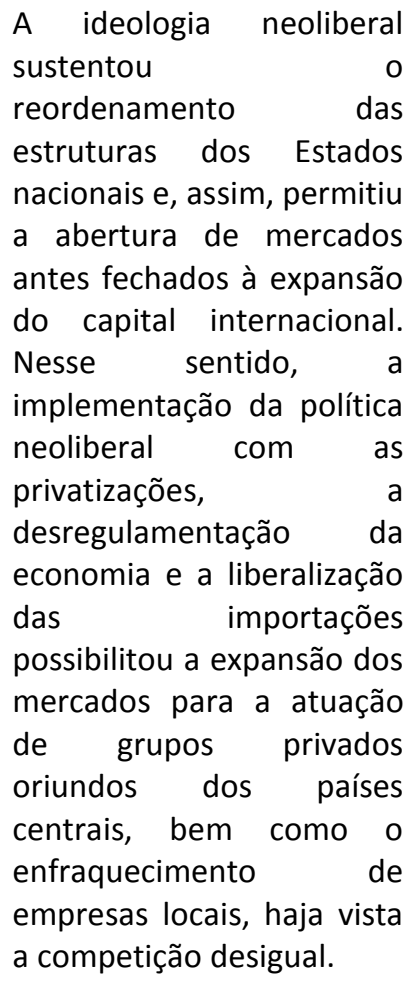

Com a política neoliberal o Estado, aos poucos, perde sua identidade de agência produtora de bens e serviços e garantia dos direitos dos cidadãos. A reforma do Estado empreendida pelo governo da época ${ }^{2}$, é firmada

\footnotetext{
1 “O neoliberalismo é um projeto político, econômico e social de caráter hegemônico que está fundamentado na subordinação da sociedade ao mercado livre e a não intervenção do poder público, sendo o mercado livre responsável pela preservação da ordem social" (NETO E MACIEL, 2004, p. 36).

${ }^{2}$ Vale dizer que essas reformas, de ordem neoliberal, iniciaram no governo de Fernando Collor de Mello (1990-1992) e tiveram
} 
pela necessidade de modernização e superação dos problemas financeiros causados pelas demandas sociais, afirmando que sem essas reformas não haveria desenvolvimento ${ }^{3}$.

No contexto dessa reestruturação a educação passa por uma nova configuração. 0 movimento de reforma acabou por transferir a educação da esfera da política para a esfera do mercado, negando sua condição de direito social e transformando-a em uma possibilidade de consumo individual, variável segundo o mérito e a capacidade dos consumidores. (GENTILI, 1998).

Assim, a educação exerce importante função para efetivar as mudanças na sociedade, ao passo em que redefine o seu papel e promove a formação de recursos humanos para alavancar o desenvolvimento econômico.

Tais reformas defendidas pelo fato de tenderem ao atendimento "das proposições do campo progressista, representado pelos movimentos sociais, e configura-se em programas e ações de governos que ressignificam as proposições populares", (LIMA, 2009, p. 19). Os anos noventa, marcado por suas mudanças propaga a concepção de que "o Estado nem tem condições de financiamento nem de gerenciamento para abarcar todas as questões sociais" (LIMA, 2009, p. 27), assim um discurso de Estado minimalista vai se propagando e, por conseguinte, a implantação de um sistema de descentralização, mormente, às políticas sociais.

\begin{abstract}
A descentralização é necessária à autonomia dos entes federados para que de certa maneira as necessidades regionais sejam mais rapidamente atendidas, mas esclarecendo, também, que de forma alguma esse processo deva desonerar o Estado de suas obrigações a ponto de o mercado ser o principal mecanismo de regulação social. (RIBEIRO e SILVA, 2012, p. 58).
\end{abstract}

Podemos apreender que as políticas de reforma do Estado e da educação, no Brasil, regidas pelo Ministério da Educação, foram

continuidade, após seu impeachment, nos governos de Itamar Franco (1992-1994) e Fernando Henrique Cardoso (1995-2002).

${ }^{3}$ Exemplo disso, é o que vivenciamos em nosso país, após o golpe de 2016, em que o governo impôs diferentes reformas nas políticas sociais, com a justificativa de impulsionar o desenvolvimento do país. viabilizadas em consonância com os organismos multilaterais. Essas políticas estão em consonância no que se refere à ascensão do privado, em que a atuação do Estado deve ser mínima para garantir uma educação de qualidade.

Chama a atenção o fato de que as medidas de reforma se apresentam muito bem estruturadas e abrangem a gestão, a formação dos professores, o currículo e seus fundamentos teóricos. As ações realizadas no campo dessas reformas demonstram a vinculação com o projeto neoliberal, fortalecendo um Estado regulador e uma educação com a participação crescente do setor privado. Seguindo essa orientação, as reformas apontam a importância de adequação das políticas de formação de professores atendendo ao novo perfil indispensável para o mercado de trabalho.

Na centralidade dessas reformas está o atendimento às orientações dos organismos multilaterais, os quais indicam a reformulação da política educacional, no Brasil e na América Latina, sob o viés de ampliação de acesso à educação básica, diversificação de cursos e instituições de ensino superior e fontes de financiamentos desses e, em contrapartida, constituem-se, de forma mascarada, processos de formação inicial e certificação dos professores de forma aligeirada e superficial. (MALACHEN; VIEIRA, 2006).

Os professores, nesse contexto, são "convidados" a assumir a reestruturação dos sistemas de ensino, ao passo que são responsabilizados pela crise da educação e ainda "expostos e indicados como alternativa ao sucesso e à superação dos problemas educacionais, desconsiderando a totalidade e complexidade das distorções regionais no campo educacional em todo o país." (RIBEIRO; SILVA, 2012, p.57).

As reformas protagonizadas nos anos de 1990 representaram terreno fértil para gestar as mudanças da década posterior. De um lado, pela ampliação do regime democrático, no qual o cidadão passa a exigir mais direitos sociais entre os quais, a democratização da educação. De outro, com a abertura política, o país também se abre ao capitalismo neoliberal, tornado hegemônico pela globalização dos mercados. É neste cenário que vão ser implementadas as novas políticas educacionais, entre as quais o novo PNE-2014-2024.

Ao considerarmos a trajetória do planejamento educacional em nosso país e os resultados alcançados pelo antigo Plano Nacional 
de Educação 2001-2010 ${ }^{4}$, percebemos a necessidade de avançarmos em muitos aspectos para garantir uma educação de qualidade. Diante de todo contexto histórico, a elaboração do Plano Nacional de Educação, como uma política de estado, ocorreu a partir da Conferência Nacional de Educação - CONAE, realizada no ano de 2010, possibilitou a participação da sociedade civil. Assim, a CONAE configurou-se em um processo de debate democrático e participativo ${ }^{5}$, com 0 objetivo de definir os rumos da educação brasileira e colher subsídios para a elaboração do Plano Nacional de Educação (PNE) para dez anos.

Como resultado da Conferência foi publicado um documento, organizado em seis eixos, que abordaram os níveis da educação brasileira com destaques para a organização do PNE. Contudo, vale destacar que participaram desse processo de planejamento algumas entidades sindicais patronais ${ }^{6}$ que, certamente, não tinham nenhum interesse em comum com os estudantes, trabalhadores em educação e movimentos sociais. (SARAIVA, 2011).

Com nova estrutura, em relação aos anteriores, extensos e pouco claros, o atual PNE promulgado pela Lei $n=13.005$, de 25 de junho de 2014 apresenta dez diretrizes, 20 metas, com estratégias para a política educacional de dez anos. O documento "linha de base" publicado pelo MEC, em 2015, destaca que as metas estão subdivididas em grupos. O primeiro grupo são metas estruturantes para a garantia do direito à Educação Básica com qualidade, e que assim promovam a garantia do acesso à universalização do ensino obrigatório e à ampliação das oportunidades educacionais. Um segundo grupo de metas diz respeito, especificamente, à redução das desigualdades e à valorização da diversidade, caminhos imprescindíveis para a equidade. 0 terceiro bloco de metas trata da valorização dos profissionais da educação, considerada estratégica para que as metas anteriores sejam atingidas, e o quarto grupo de metas refere-se ao Ensino Superior.

A promulgação do PNE desencadeou um movimento de renovação na educação, de modo que as metas e estratégias traçadas para os dez anos contemplam desafios atuais das diferentes etapas da Educação Básica e profissionalização docente. $O$ atual PNE apresenta-se como um

\footnotetext{
${ }^{4}$ Aprovado pela Lei no 10.172, de 09 de janeiro de 2001.

${ }^{5}$ Ancorado pela Constituição Federal de 1988 e a LDB 9.394/96.

6 A Confederação Nacional dos Estabelecimentos de Ensino, a Confederação Nacional dos Empresários e a Confederação Nacional da Indústria fizeram parte da Comissão Organizadora da CONAE.
}

plano ousado e um instrumento de luta. Partimos do pressuposto de que esse PNE, enquanto política de estado, preconiza políticas de formação docente e, portanto, orientações para as políticas de profissionalização docente. Das vinte metas, duas tratam, especificamente, da formação docente, as metas 15 e 16.

Assim, retornamos a questão dos professores na promoção dessas melhorias, por compreendermos o papel do Estado em pensar políticas educacionais e concretizar ações que viabilizem a formação inicial e continuada de qualidade. Compreende-se, nessa relação, o professor enquanto profissional da área da educação, responsável e dedicado ao seu trabalho, com necessidade de aperfeiçoar-se, numa formação continuada, e que precisa, principalmente, de políticas públicas que the viabilizem e garantam o exercício dessa profissão.

A partir das políticas públicas, implementadas ou ausentes, com base nas análises de conteúdos que realizamos, desenvolvemos a problemática, estabelecendo aproximações ou distanciamentos, assim como avanços e desafios em relação às políticas que viabilizam ou não a profissionalização docente, em desenvolvimento em nosso país.

\section{ENTRE O TEXTO E O CONTEXTO: O QUE DIZEM OS DOCUMENTOS?}

Tomamos como conceito norteador dessa discussão, alguns conceitos: profissionalismo é o compromisso do professor com o trabalho que desenvolve, com o ato educativo e com o projeto pedagógico da escola. (LIBÂNEO, 1998). Profissionalidade é o aperfeiçoamento docente na busca de um desenvolvimento profissional e pessoal. Sacristán (1993), ensina que para mudarmos as bases da profissionalidade tornamse necessárias a viabilização e a implementação de programas que não somente venham a suprir as falhas de conhecimentos de um professor, mas que esta prática seja compreendida como um modelo de desenvolvimento pessoal, profissional e humano, pautado em situações concretas. Nessa direção, busca-se a profissionalização que é um processo através do qual os trabalhadores melhoram seu estatuto, elevam seus rendimentos e aumentam o seu poder de autonomia. (NÓVOA, 1992).

Assim, contribuirá para conquistar seu status quo, sua posição social, a partir das políticas públicas a eles direcionadas. Portanto, a profissionalização está relacionada às políticas 
públicas educacionais, ao contexto histórico e social vigente e a valorização da profissão nas políticas sociais. Porquanto, a profissionalização está atrelada às políticas públicas educacionais, ao contexto histórico e atual e à valorização atribuída à profissão docente.

Sabemos que a formação inicial é essencial para embasar teoricamente e capacitar os profissionais em relação à sua prática docente. Pereira (2008) atribui um conceito à formação desse profissional, denominando formação inicial ou formação acadêmico-profissional, o início deste processo contínuo, no qual o indivíduo estabelece uma relação entre a aprendizagem e a formação. A aprendizagem tem por objetivo formar e transformar o indivíduo em um ser prático e reflexivo, sendo capaz de compreender o meio em que está inserido.

A formação inicial, dentro do contexto educacional, é fundamental para que profissionais capacitados em relação à sua prática docente, sejam capazes de ensinar de maneira a colaborar com o processo de aprendizagem dos alunos, mas, para que isso ocorra, é preciso um currículo que favoreça uma relação entre os polos teoria e prática, que nesse caso são indissociáveis.

Por isso, destacamos que essa formação necessita estar articulada aos processos de ensino e aprendizagem e na organização e gestão da Educação Básica. De nada adianta formar um professor distanciado do contexto socioeducacional em que, futuramente, irá atuar. Sob esse prisma, Oliveira (2011, p. 34) aponta que "as políticas educacionais recentes no Brasil têm manifestado a necessidade de dedicar maior atenção ao magistério público para melhor responder às novas demandas apresentadas às escolas [...]." 7 O cenário referente à formação docente no Brasil teve mudanças a partir da Lei de Diretrizes e Bases da Educação Nacional (LDB) de 1996, que estabeleceu a formação em curso superior como como requisito ideal para exercício

\footnotetext{
7 Podemos fazer referência à Base Nacional Comum Curricular, visando à renovação e ao aprimoramento da educação básica como um todo, assume um forte sentido estratégico nas ações de todos os educadores, bem como gestores de educação brasileira. Com efeito, a formação inicial e continuada dos professores muda sua estrutura e passa a seguir Diretrizes específicas. Vale refletir sobre a referência da BNCC, pois a Constituição Federal de 1988 fixa conteúdos mínimos para o ensino fundamental, conforme Art. 10 "Serão fixados conteúdos mínimos para o ensino fundamental, de maneira a assegurar formação básica comum e respeito aos valores culturais e artísticos, nacionais e regionais", que como sabemos devem ser estabelecidos nas Diretrizes Curriculares Nacionais e contemplados no currículo.
}

da profissão docente ${ }^{8}$. Após a LDB, outros atos legais, como as Resoluções CNE/CP 1/2002 e $2 / 2002$, instauraram uma nova proposta de formação de professores que fundamentam as Diretrizes Curriculares Nacionais específicas aos cursos de licenciatura, trazendo ideias inovadoras acerca do tema com reflexões mais amplas, contemplando a pesquisa como princípio educativo e a prática como componente curricular.

No entanto, as lacunas na formação inicial, que, por vezes, é construída de maneira distanciada da Educação Básica, ainda são um dos grandes entraves na melhoria da qualidade da educação. Sabendo que a formação inicial não é suficiente para atender a complexidade e a dinâmica do processo de ensino e aprendizagem, faz-se necessária e fundamental a formação continuada, embasada em múltiplos saberes que abarcam a docência. Compreendemos a formação continuada como uma possibilidade de reflexão e de (re) estruturação da prática docente. Para que tal formação se efetive é essencial sobretudo, considerar as especificidades de cada local escola e corpo docente. O professor, através de seus conhecimentos, dos saberes, das suas competências e habilidades, dá sentido à sua prática e à sua identidade. Por isso, urge a necessidade de os docentes serem reconhecidos como sujeitos que possuem, utilizam e produzem saberes específicos ao seu ofício, ao seu trabalho.

Nomeadamente, sobre a formação docente, o Plano Nacional de Educação (20142024), aborda a categoria em duas metas $^{9}: 15-$ Formação de professores, com treze estratégias; e 16 - Formação continuada e pós-graduação de professores, com seis estratégias.

Ao abordarmos, na íntegra, o texto da meta 15 , que propõe:

garantir, em regime de colaboração entre a União, os Estados, o Distrito Federal e os Municípios, no

\footnotetext{
${ }^{8}$ Embora seja desejável a formação superior, ainda é admitida, como formação mínima para o exercício do magistério na educação infantil e nos 5 primeiros anos do ensino fundamental, a oferecida em nível médio, na modalidade normal, como se as etapas iniciais da Educação Básica não necessitam de professores com formação em nível superior. Por mais que o PNE tenha adotado a graduação plena - licenciatura em pedagogia, para a educação infantil e os anos iniciais do fundamental, e licenciatura em área de conhecimento específica, para os anos finais do fundamental e o ensino médio como a formação universalmente almejada para 2024. (Redação da Lei no 12.796, de 2013).

${ }^{9}$ A escolha dessas metas justifica-se pelo fato de abordarem, com maior ênfase, o tema da formação e valorização dos profissionais da educação. Contudo, é importante destacar que, em praticamente todo o PNE, há estratégias que envolvem essas categorias.
} 
prazo de 1 (um) ano de vigência deste $P N E$, política nacional de formação dos profissionais da educação de que tratam os incisos I, II e III do caput do art. 61, da Lei no 9.394, de 20 de dezembro de 1996, assegurado que todos os professores e as professoras da educação básica possuam formação específica de nível superior, obtida em curso de licenciatura na área de conhecimento em que atuam.

A meta em tela destaca a obrigatoriedade de formação em nível superior, em cursos de licenciatura, por todos os professores da Educação Básica, o que pressupõe um avanço na concepção da formação inicial do profissional docente, haja vista, a perspectiva de superação de uma formação em nível médio. Ao encontro dessa proposta, a meta garante a construção de uma política nacional de formação dos profissionais da educação, já no primeiro ano de vigência do Plano $^{10}$ com a ambição de superar . Com efeito:

Uma perspectiva
fragmentada da formação
de educadores no país,
caracterizada
proliferação de uma
miríade de iniciativas
pontuais - e, por vezes,
desconexas[...]. Espera-se
que a pluralidade de
modelos seja norteada pela
unidade de objetivos e pela
organicidade dada por uma
política nacional. (BRITTO,
2017, p. 231).

Nas palavras de Scheibe (2016, p.1), “o cenário é desafiador, se considerarmos o percentual expressivo dos professores brasileiros que ainda não tem a formação mínima requerida para o nível ou a disciplina em que atuam." (SCHEIBE, 2016, p. 1).

Em relação a essa questão, utilizamo-nos, também, dos indicadores fornecidos pelo

\footnotetext{
${ }^{10}$ O PNE completou um ano de vigência em 25 de junho de 2015 e o Decreto no 8.752 que instituiu a Política Nacional de Formação dos Profissionais da Educação foi aprovado em 09 de maio de 2016, quase um ano depois, ou seja, a exemplo do próprio Plano, tal política foi efetivada no plano legal decorrido quase dois anos de aprovação do PNE.
}

Observatório do PNE (2017) ${ }^{11}$, os quais apontam que $78,3 \%$ dos professores da Educação Básica detinham formação com Ensino Superior, o que significa que aproximadamente um quarto dos professores lecionam mesmo sem ter formação neste nível. E, de acordo com o relatório do INEP (2016), sobre o monitoramento do PNE no biênio 2014-2016, pouco mais da metade das docências registradas no Censo Escolar de 2015, em toda a educação básica, atendia ao critério da meta 15: ainda que mais de três quartos dos professores tivessem diploma de nível superior, somente $52,5 \%$ tinham formação específica na disciplina ministrada.

\section{Cabe destacar que}

[...] existe a necessidade de formar/certificar um enorme número de professores no Brasil, ou seja, há um déficit de profissionais da educação básica (especialmente, em algumas áreas do conhecimento e, particularmente, em algumas regiões do país). Por outro lado, existe uma baixa ocupação de vagas nos cursos já existentes (e, por via de consequência, há cursos de licenciatura sendo fechados em várias instituições de ensino superior do país) e um número relativamente baixo de graduados em relação ao número de vagas oferecidas. (PEREIRA, 2013, p. 81).

Diante desses dados e, numa perspectiva de qualificar a educação brasileira, não podemos admitir que a formação docente siga num caminho de certificação, na contramão de uma formação de qualidade. Por outro lado, conforme aponta Pereira (2013, p. 81), "a dificuldade dos alunos manterem seu sustento durante a graduação, a baixa expectativa de renda em relação à futura profissão e o declínio do status social da docência" contribuíram para aumentar

\footnotetext{
${ }^{11}$ O Observatório do PNE é uma plataforma online que tem como objetivo monitorar os indicadores referentes a cada uma das 20 metas do Plano Nacional de Educação (PNE) e de suas respectivas estratégias, e oferecer análises sobre as políticas públicas educacionais já existentes e que serão implementadas ao longo dos dez anos de vigência do Plano. Esses dados são apresentados pela plataforma com base em 2017. Disponível em: http://www.observatoriodopne.org.br/
} 
as taxas de evasão dos cursos de licenciatura, permanecendo em constante crise, atingindo instituições públicas e privadas.

Nesse contexto, a meta 15 estabelece algumas estratégias. Tais estratégias, definidas para efetivar essa meta, propõem diversas ações que partem desde a criação de cursos e programas até a ampliação e consolidação de outros, fazendo o uso de "verbos bem mais incisivos", que apontam novos horizontes para a formação, porém novos desafios para a concretude do que pressupõem e, talvez, passem a ser um "problema a ser enfrentado." (PEREIRA, 2013, p. 84).

Com efeito, são ações ousadas que visam ao atendimento da demanda de formação inicial conforme as necessidades do país, bem como à reestruturação dos currículos de formação dos cursos de licenciatura e renovação pedagógica, valorizando as práticas de ensino e estágios, num processo de articulação entre Ensino Superior e Educação Básica, estimulada a renovação pedagógica e a incorporação das modernas tecnologias de informação e comunicação, o que pressupõe um processo de renovação à trajetória de formação inicial, articulando conhecimentos científicos, técnicos, pedagógicos e tecnológicos no ambiente de formação e atuação profissional, pois "a formação de professores tem de ser tratada - em um espaço e tempo de diálogo e de articulação, de interatuação entre a educação superior e a educação básica - como uma questão complexa e uma política pública em movimento[...]." (LUCE, 2017, p. 186). Ademais, salienta a garantia da plena implementação das diretrizes curriculares por meio da avaliação, regulação e supervisão da educação superior. Todavia, vale ressaltar que, um instrumento de avaliação não atribui qualidade ao curso e sim "as condições em que o mesmo é ofertado, a qualificação de seu corpo docente e as condições que os alunos têm para fazê-lo." (PEREIRA, 2013, p. 84).

Uma vez que está situada "a definição e a concretização da formação de professores no cerne da discussão sobre a política nacional curricular da educação básica, porque a política de currículo e a política de formação são estruturantes da qualidade da educação. Uma é conteúdo e, de certa forma, estratégia da outra." (LUCE, 2017, p. 186).

Contudo, é importante avançar em algumas questões. Considerando as alterações na LDB, nos últimos anos, sobre a garantia da universalização da educação infantil ao ensino médio, a demanda pela formação de professores aumentou e continuará aumentando nos próximos anos, o que demandará num "imenso esforço do poder público e das instituições formadoras para sua cobertura com profissionais formados nas diversas áreas e níveis de ensino." (FREITAS, 2014, p. 431). Nesse contexto, segundo a autora, serão necessários mais de 200 mil professores $^{12}$, portanto, aponta para a necessidade de expandir o ensino superior público, com prioridade para os cursos de licenciatura, com indissociabilidade entre ensino, pesquisa e extensão em detrimento à ampliação de instituições privadas, implantadas, sobretudo, na década de 1990, sob o viés das políticas neoliberais, nas quais a pesquisa não é atividade obrigatória. (FREITAS, 2014) A esse respeito, a Meta 15, conta com uma estratégia específica (15.1) em que os entes federados precisam atuar em conjunto, a partir de um plano estratégico, com as necessidades de formação e a capacidade de atendimento das IES públicas e comunitárias existentes nesses espaços. Todavia, não especifica a modalidade (presencial/distância) do curso de licenciatura em que os professores devem buscar tal formação.

Na sequência, as estratégias 15.2 e 15.3, estabelecem a necessidade de consolidar o financiamento estudantil e a ampliação do programa permanente de iniciação à docência. 0 fato de ampliar o financiamento estudantil, sem dúvidas, é uma ação importante para ensejar as possibilidades de acesso ao ensino superior, porém o mesmo pode ser solicitado para cursos em instituições privadas, as quais, nem sempre, ofertam e garantem uma formação de qualidade em seus cursos de licenciatura. Pensamos que essa manutenção e ampliação estabelecidas pelo PNE poderia ser assumida pelo poder público como etapa transitória a ser superada e assim expandir as políticas de formação dos profissionais do magistério em IES públicas e comunitárias, fortalecendo a formação e valorização desses profissionais. (FREITAS, 2014).

O programa de iniciação à docência, foi um programa de caráter inovador, proporcionando um avanço na inserção e vivência dos estudantes de licenciatura à realidade escolar,

\footnotetext{
12 Além disso, considerando dados do IBGE (2013), 46,1\% dos professores das redes estaduais e municipais de ensino possuem faixa etária acima de 40 anos, o que aponta uma demanda expressiva de novos professores nos próximos anos para atender às vagas remanescentes.
} 
visto que, somente os estágios, não têm se mostrado suficiente.

Sobre esse programa nos valemos das ideias de Freitas (2014) que enfatiza a necessidade de garantia a todos os estudantes que postulam a licenciatura, condições de igualdade, permanência e êxito nos estudos e iniciação à carreira com apoio à construção da identidade profissional. Nesse viés destaca que o Pibid deve, portanto, "consolidar-se como política de Estado extensiva a todos os estudantes e a todos os docentes das licenciaturas, superando, definitivamente, a etapa de programa pontual, e com a oferta de bolsas, às quais apenas alguns professores e estudantes possuem acesso." (FREITAS, 2014, p. 432). Esse não é um desafio pequeno, mas como dito em diversas pesquisas e avaliações realizadas por professores e estudantes, é um programa de muito sucesso e de grande valia à formação dos licenciados, por isso "seria a hora de alçar seus processos de trabalho e os recursos que os possibilitam à condição de institucionalização." (LUCE, 2017, p. 189). Para que tal proposta se efetivasse tornar-se-ia imprescindível repensar essa política de tal maneira que fosse possível contemplar a todos, inclusive, na expansão da iniciação científica com pesquisa e extensão, considerando que "o triângulo virtuoso de ensino, pesquisa e extensão é a base da excelência na formação inicial e continuada de professores." (LUCE, 2017, p. 189). Uma das alternativas propostas pela autora seria a transposição da dinâmica de trabalho do programa Pibid ao Projeto Pedagógico de Cursos das licenciaturas e Projeto Político Pedagógico das escolas.

Ao propor como estratégia a implementação de cursos e programas especiais para assegurar a formação em nível superior, em função da necessidade urgente de se habilitar aqueles que, em grande número, estão em sala de aula como docentes, corre-se o risco de favorecer a improvisação na formação, possibilitando que profissionais de diferentes áreas sejam habilitados para a docência mediante uma complementação pedagógica mínima, o que prejudica o status social da profissão, uma vez que admite uma formação superficial e supervalorização da experiência prática em detrimento de conhecimentos científicos da área de atuação, o que é inconcebível em outros campos profissionais. Sobre isso, cabe destacar o que nos diz Pereira (2013, p. 86) "esse esquema é uma infeliz legitimação do "bico" na profissão docente, uma vez que profissionais egressos de outras áreas, que não optaram, de início, pela carreira do magistério, provavelmente, permanecerão na profissão enquanto não conseguirem "algo melhor para se fazer." Ademais, perpetua-se uma política emergencial de formação superior de professores que estão em exercício, justificando a expansão da educação a distância para a formação massiva de professores, o que contraria a própria LDB, art. $62, \S 3 \%$, o qual determina que "a formação inicial de profissionais de magistério dará preferência ao ensino presencial, subsidiariamente fazendo uso de recursos e tecnologias de educação a distância"13. (BRASIL, 2009).

Em relação à formação continuada a meta 16 propõe:
Formar, em nível de pós- graduação, 50\% (cinquenta por cento) dos professores da educação básica, até o último ano de vigência deste PNE, e garantir a todos (as) os (as) profissionais da educação básica formação continuada em sua área de atuação, considerando as necessidades, demandas e contextualizações dos sistemas de ensino.

Atualmente, apenas 35\% dos professores da Educação Básica possuem Pós-Graduação, segundo dados do Censo Escolar (2016). As estratégias pensadas para essa meta vão ao encontro da consolidação da política nacional de formação, definindo diretrizes, áreas prioritárias, instituições formadoras e processo de certificação, além da expansão de programas direcionados ao acesso a bens culturais pelo magistério público e a ampliação de bolsas de estudo para o nível de pós-graduação aos professores da Educação Básica.

Como podemos constatar são estratégias que visualizam novas possibilidades e a ampliação de horizontes na formação continuada, na perspectiva de qualificar os processos de formação e atuação profissional. Mas, por outro lado, a formação continuada esteve restrita à realização de cursos de pós-graduação (lato e stricto sensu), o que não é negativo, uma vez que

\footnotetext{
13 O Censo da Educação Superior de 2015 registrou 560 mil matrículas de graduação a distância na área de educação (cerca de um terço do total), das quais 342 mil em cursos de pedagogia, em sua maioria nas instituições privadas.
} 
têm se expandido os mestrados profissionais, desenvolvidos em parceria com as escolas para oferta de formação continuada e assim os mestrandos podem apoiar as licenciaturas no campo da prática. Luce (2017) elenca contribuições a essa reflexão quando explicita que esses programas são uma oportunidade de formação continuada, desde que contem com uma concepção, realmente adequada, permitirão como eixo de formação o próprio espaço de trabalho, com projeto de pesquisa-ação a ser realizada na escola em que o docente está em exercício, nas horas de trabalho, o que parece ser auspicioso. Para Freitas (2014, p. 435), tais programas visam "ao fortalecimento da aproximação entre educação básica èo ensino superior com a compreensão de que as escolas são espaços privilegiados de formação, produção de saberes e conhecimentos."

Mas também, é pertinente considerar enquanto formação ,outros processos que ensejam o acesso a diferentes recursos didáticos, tecnológicos, bem como acesso aos bens culturais, e que estes sejam institucionalizados nas redes de ensino e na carreira profissional, posto que se apresenta como um desafio expandir cursos de pós-graduação (lato e stricto sensu), definindo cursos e áreas prioritárias, para atender a grande maioria dos profissionais do magistério da Educação Básica e, também por existir limitações no acesso de formação continuada, especialmente, cursos de pós-graduação stricto sensu, que possibilitam uma melhoria significativa na formação e no trabalho do profissional docente, mas que exigem maior tempo de dedicação e estudos e, portanto, a necessidade de liberação das escolas para fazer esses cursos. No entanto, existem barreiras que os próprios sistemas interpõem para que seus professores tenham liberação para dar continuidade ao seu processo formativo, ou seja, as condições de trabalho interferem fortemente na disposição e abertura para novas informações e estudos. (SCHEIBE, 2016).

O desafio de pensar uma política para "formação dos formadores de profissionais do magistério da educação básica, é imediato, expandindo a concepção de formação do docente universitário como exclusivamente de pesquisador - para a compreensão de formação de profissionais formadores do magistério da educação básica." (FREITAS, 2014, p. 436).

Diante do exposto, articuladas às metas, aqui apresentadas e, respectivamente, às suas estratégias explicitadas no PNE (2014-2024), foram homologadas pelo MEC, em 24 de junho de 2015, às novas Diretrizes Curriculares Nacionais para a Formação Inicial e Continuada dos Profissionais do Magistério da Educação Básica, resultado de debates e discussões que, por mais de uma década, foram objeto de estudo no Conselho Nacional de Educação, por meio de uma Comissão Bicameral ${ }^{14}$. Considerando as diferentes concepções e embates no campo educacional, bem como os marcos legais, com destaque para a CF 1988, a LDB e o PNE (2014-2024), o processo de construção das novas Diretrizes foi desencadeado com o objetivo de garantir maior organicidade para a formação inicial e continuada dos profissionais do magistério da educação básica e, por isso, assinala um momento de transição para essas políticas.

Tais discussões também foram resultantes das deliberações da CONAE, a qual reafirmou a necessidade de um Sistema Nacional de Educação, articulado às políticas educacionais e à valorização dos profissionais da educação, destacando a necessidade de uma base comum nacional para a formação inicial e continuada aos professores, como forma de garantir uma sólida formação teórica e interdisciplinar em educação, formando professores para atuar nas diferentes etapas da Educação Básica. Nessa perspectiva, cabe destacar o que nos diz Dourado (2015), quando afirma que é preciso garantir

Uma concepção de
formação pautada tanto
pelo desenvolvimento de
sólida formação teórica e
interdisciplinar em
educação de crianças,
adolescentes, jovens e
adultos (as) e nas áreas
específicas de
conhecimento científico
quanto pela unidade entre
teoria e prática e pela
centralidade do trabalho
como princípio educativo
de formação profissional,
como também pelo
entendimento de que a
pesquisa se constitui em
princípios cognitivo e
formativo e, portanto, eixo

\footnotetext{
${ }^{14}$ O CNE é composto pelas Câmaras de Educação Superior e de Educação Básica. A Comissão Bicameral de Formação de Professores é constituída por conselheiros das duas Câmaras, com a finalidade de desenvolver estudos e proposições sobre a temática.
} 
nucleador dessa formação.

As novas DCNs caracterizam-se como uma política nacional, com escopo bastante abrangente, resultado de inúmeras discussões ao longo da última década, que com a aprovação do PNE a mesma pode ser publicada. Estando articulada ao PNE, especialmente, às metas 15 , 16,17 e 18, e suas estratégias que configuram as bases para a formulação de uma política nacional de formação dos profissionais da educação, a Resolução no 2/CNE/CP/2015 apresenta-se como um componente essencial para a profissionalização docente.

A formação de profissionais docentes da Educação Básica, por se caracterizar como proposta de nova política educacional, tem se constituído em campo de disputas de concepções, dinâmicas, políticas e currículos, sob influências de diferentes instâncias, com maior ou menor poder de interferência de acordo com o momento histórico. Mas, de maneira geral, todos apontam para a necessidade de repensar a formação desses profissionais. Numa perspectiva de maior organicidade das políticas, as novas Diretrizes apresentam a necessidade de avançar nos marcos referenciais em vigor, no que tange à formação inicial e continuada, "por meio de ações mais orgânicas entre as políticas e gestão para a educação básica e a educação superior, incluindo a pós-graduação e, nesse contexto, para as políticas direcionadas à valorização dos profissionais da educação. " (DOURADO, 2015, p. 306).

Para atender a essa concepção, as novas DCNs sinalizam como essencial maior articulação, por meio de fóruns, entre instituições formadoras e Educação Básica, para a elaboração e desenvolvimento de projetos formativos, definindo que a formação inicial e continuada deve contemplar:

I. Sólida formação teórica e interdisciplinar dos profissionais.

II. A inserção dos estudantes de licenciatura nas instituições de educação básica da rede pública de ensino, espaço privilegiado da práxis docente;

III. O contexto educacional da região onde será desenvolvido;
IV. Atividade de socialização e avaliação dos impactos;

V. À ampliação e ao aperfeiçoamento do uso da língua portuguesa e à capacidade comunicativa, oral e escrita, como elementos fundamentais da formação dos professores e à aprendizagem de Libras;

VI. As questões socioambientais, éticas, estéticas e relativas a diversidade étnico-racial, de gênero, sexual, religiosa, de faixa geracional e sociocultural como princípios de equidade. (BRASIL, 2015).

Este cenário clama por um novo conceito e panorama de formação docente, visto que se propõe a articulação entre Educação Básica e Educação Superior na elaboração dos projetos de formação. Podemos pensar essa nova política educacional como um avanço importante, sobretudo, nas políticas de formação docente, pois assim, descortinam-se novas possibilidades de contemplar conhecimentos teóricos, interdisciplinares e pedagógicos, com relações concretas entre teoria e prática, ressignificando a práxis docente desde a formação inicial. Conforme enfatiza Dourado (2015, p. 307)

Tais questões implicam
novos horizontes à
dinâmica formativa dos
profissionais do magistério
da educação básica, pois a
garantia do direito à
educação a grupos e
sujeitos historicamente
marginalizados exige
transformação na forma
como as instituições de
educação básica e superior
estruturam seus espaços e
tempos, suas regras e
normas, incorporam novos
materiais e recursos
pedagógicos.

É fundamental que as instituições formadoras institucionalizem um projeto de formação com identidade própria, sob um conceito de formação fundado no domínio dos conhecimentos científicos e didáticos, contemplando a indissociabilidade entre ensino,

${ }^{15}$ Grifos das autoras. 
pesquisa e extensão, articulado às instituições de Educação Básica, considerando uma "base comum nacional, sem prejuízo de base diversificada, pautada pela concepção de educação como processo emancipatório e permanente" (DOURADO, 2015, p. 307), reconhecendo o trabalho docente, bem como as divergentes realidades de instituições e profissão.

Na elaboração desse projeto formativo é essencial considerar a realidade histórica e social e evitar a hierarquização de saberes e dicotomia teoria/prática. Ademais, as DCNs sublinham que a formação inicial deverá ser ofertada, preferencialmente, de forma presencial (quesito que não havia ficado claro no PNE) e prescrevem um considerável incremento à carga horária dos cursos de licenciatura, especialmente, às dimensões pedagógicas que não devem ser inferiores à quinta parte da carga horária total do curso. "Essa disposição legal será um dos desafios das instituições formadoras, pois reunir todas essas orientações em uma matriz curricular em 8 semestres, especialmente para os cursos noturnos não é tarefa fácil." (HONÓRIO et al, 2017, p. 1747).

Segundo as novas DCNs, ao final de sua formação inicial e continuada, o egresso deverá contemplar conhecimentos teóricos e práticos, portanto plurais, sendo resultado do projeto pedagógico do processo de formação e do exercício profissional, "fundamentado em princípios de interdisciplinaridade, contextualização, democratização, pertinência e relevância social, ética e sensibilidade afetiva e estética." (DOURADO, 2015, p. 307). Dessa forma, permitindo que tenha acesso e conhecimento sobre a instituição educativa, a pesquisa, o seu campo de atuação, a gestão educacional e de instituições de educação básica. Evidencia-se, nesse novo paradigma de formação, a necessidade de se ampliar e de abranger as diferentes características e dimensões da docência. A educação é compreendida como processo de emancipação e a escola como lócus da práxis docente.

Sobre a formação continuada, as novas Diretrizes apontam para a necessidade de compreender as dimensões coletivas, organizacionais e profissionais, o repensar do processo pedagógico, dos saberes e valores. Reconhecem como processo contínuo e que pode ocorrer em diferentes espaços e momentos, por meio de atividades de extensão, grupos de estudo, reuniões pedagógicas, cursos, programas que vão além da formação mínima exigida, "tendo como principal finalidade a reflexão sobre a prática educacional e a busca de aperfeiçoamento técnico, pedagógico, ético e político do profissional docente." (DOURADO, 2015, p. 312). O conteúdo desse documento amplia as concepções apresentadas pelo PNE, complementando e esclarecendo questões pontuais sobre a organização da formação inicial, prioritariamente de forma presencial, e formação continuada específica e ampla.

A formação continuada faz-se necessária para possibilitar a (re) construção da identidade profissional, bem como para renovar os saberes docentes, para que esses possam servir de subsídios para o aperfeiçoamento de sua prática em sala de aula. Nesse sentido é imperativo pensar a formação continuada, considerando cada contexto e suas especificidades e, portanto, os temas abordados não devem ser generalizados, pois para poder despertar o interesse dos docentes pela formação continuada é preciso abordar questões que estejam vinculadas à sua realidade profissional. Dessa maneira, cabe salientar que:

Somente quando o
professorado vê que o
novo programa formativo
ou as possíveis mudanças
da prática que lhes é
oferecida repercutem na
aprendizagem de seus
estudantes, mudam suas
crenças e atitudes de
forma significativa e supõe
um benefício para o
alunato e a forma de
exercer a docência, então,
abre-se a forma de ver a
formação não tanto como
uma "agressão" externa,
mas como um benefício
individual e coletivo.
(IMBERNÓN, 2009, p. 27).

Nessa perspectiva, é necessário repensar a formação continuada, reestruturá-la de modo que incentive os professores a participar, ativamente, desse novo processo de aprendizagem e profissionalidade. Essa formação deve estar em constante atualização e inovação, permitindo uma repercussão nos projetos educacionais, nos quais estão envolvidos professores e instituições. A reestruturação refere-se às posturas críticas, que busquem o 
novo e que permitam sonhar em alcançá-lo. Segundo Imbernón (2009, p. 37):

$$
\begin{aligned}
& \text { O objetivo dessa } \\
& \text { reestruturação deveria ser } \\
& \text { ressituar o professorado } \\
& \text { para ser protagonista ativo } \\
& \text { da sua formação em seu } \\
& \text { contexto trabalhista, no } \\
& \text { qual deve combinar as } \\
& \text { decisões entre o prescrito e } \\
& \text { o real, aumentar seu } \\
& \text { autoconceito, sua } \\
& \text { consideração e seu status } \\
& \text { trabalhista e social. }
\end{aligned}
$$

O conceito atribuído à formação dos profissionais do magistério da educação básica, de acordo com as novas DCNs, apresenta-se de uma forma indispensável a um projeto diferenciado da educação brasileira, visto que avança para uma concepção ampla entendida a partir da formação inicial e continuada, bem como pela valorização. Assim, a formação continuada se apresenta como um direito, tendo a centralidade do trabalho docente como práxis e, portanto, vislumbrar um novo horizonte à profissionalização docente, que é um processo no qual formação inicial, formação continuada e valorização caminham entrelaçadas. Sobre isso, corroboram as contribuições de Nóvoa (1992, p.10) ao afirmar que

A formação de professores
ocupa um lugar central
neste debate, que só se
pode travar a partir de uma
determinada visão (ou
projecto) da profissão
docente. É preciso
reconhecer as deficiências
científicas e a pobreza
conceptual dos programas
actuais de formação de
professores. E situar a
nossa reflexão para além
das clivagens tradicionais
(componente científica
versus componente
pedagógica, disciplinas
teóricas versus disciplinas
metodológicas, etc.),
sugerindo novas maneiras
de pensar a problemática
da formação de
professores. de

Na direção de uma política mais sistêmica, as DCNs representam um marco importante. Percebemos uma articulação com o Plano
Nacional de Educação e suas metas, na busca de construir uma base comum nacional para a formação dos profissionais do magistério, bem como uma coerência com um planejamento educacional que precisa ser assumido enquanto política de Estado. A Resolução CNE/CP no 2/2015, inicialmente, definiu que em um prazo de dois anos, a contar da data de sua publicação, os cursos em funcionamento deverão se adaptar às novas DCNs. Em 2017, o CNE publicou ato legal ampliando esse prazo para três anos e, em 2018, nova Resolução foi publicada, ampliando esse prazo para quatro anos. ${ }^{16}$

Diante disso, pensamos ser pertinente destacar que, embora o texto da Resolução no 2 $\mathrm{CNE} / \mathrm{CP} / 2015$, apresenta clareza ao determinar o caminho a ser seguido pelas instituições formadoras, na elaboração e desenvolvimento de um projeto mais orgânico de formação inicial e continuada, são grandes os desafios que se descortinam no campo da formação, pois para além de uma efetiva política de formação, é fundamental implantar o Sistema Nacional de Educação e garantir recursos para cumprir a meta de $10 \%$ do PIB para a educação, investindo em carreira e melhores condições de trabalho para os professores. Tais processos se apresentam como balizadores na perspectiva de maior organicidade para as políticas e gestão da educação nacional.

Corroborando, Scheibe (2016) alerta que para garantir uma formação de qualidade a todos os profissionais da educação, em sua área de atuação, urge a necessidade da finalização do documento em construção sobre a política nacional de formação dos profissionais da educação, mas não só, é preciso também alinhar os planos estaduais e municipais com as metas e estratégias nacionais para que se torne possível materializar as ações propostas.

Em consonância às palavras da autora e conforme preconizam as metas 15 e 16 do PNE (2014-2024), foi publicado o Decreto no 8.752, em 09 de maio de 2016, que dispõe sobre a Política Nacional de Formação dos Profissionais da Educação Básica ${ }^{17}$, revogando o Decreto 6.755, de 2009 que instituiu a Política Nacional de Formação de Profissionais do Magistério da Educação Básica

\footnotetext{
${ }^{16}$ A Resolução № 3, de 3 de outubro de 2018 alterou o prazo, previsto no Art. 22, da Resolução CNE/CP no 2, de 1ㅇ de julho de 2015, que passou a ter a seguinte redação: “Art. 22. Os cursos de formação de professores, que se encontram em funcionamento, deverão se adaptar a esta Resolução no prazo improrrogável de 4 (quatro) anos, a contar da data de sua publicação".

${ }^{17}$ Cabe esclarecermos que essa legislação se refere a todos os profissionais da Educação Básica, mas que nesse artigo abarcamos somente os profissionais docentes da Educação Básica.
} 
e disciplinou a atuação da Coordenação de Aperfeiçoamento de Pessoal de Nível Superior CAPES no fomento a programas de formação inicial e continuada. Esse ato legal dispõe, inicialmente, seus princípios e objetivos que contemplam a garantia de um padrão de qualidade nos cursos de formação inicial e continuada, fortalecidos na articulação entre teoria e prática, com domínio de conhecimentos científicos, pedagógicos e técnicos específicos, o entendimento dos profissionais da educação como agentes fundamentais do processo educativo, com a sua consequente valorização traduzida em políticas permanentes de estímulo à profissionalização e à progressão na carreira docente. Enfatiza, de igual forma, em seus princípios, o compromisso com a aprendizagem na idade certa e ensino adequado ao ano cursado pelos alunos o que é contraditório, pois, além de abandonar o conceito de ciclo de formação, conforme as Diretrizes da Educação Básica ${ }^{18}$, centraliza, quase que de forma exclusiva, a responsabilidade aos docentes e à política de formação sobre o aprendizado dos alunos.

Outra questão que merece análise é o fato de o Decreto abrir possibilidade de apoio financeiro às instituições privadas para oferta do Programa Nacional de Formação de Professores da Educação Básica - PARFOR, na medida em que essa política era direcionada, exclusivamente, às IES públicas ou comunitárias. Nesse caso, lembramos da estratégia 15.1 do PNE, que estabelece a necessidade de

Atuar, conjuntamente, com
base em plano estratégico
que apresente diagnóstico
das necessidades de
formação de profissionais
da educação e da
capacidade de
atendimento, por parte de
instituições públicas e
comunitárias de educação
superior existentes nos
Estados, Distrito Federal e
Municípios, e defina
obrigações recíprocas entre
os partícipes. (BRASIL,
2014).

18 Resolução № 4, de 13 de julho de 2010: define Diretrizes Curriculares Nacionais Gerais para a Educação Básica, supõe organização curricular que oferece tempos diferentes adequados às condições reais dos estudantes, como instrumento de pleno desenvolvimento e aprendizado de todos, com sucesso, ao final de um ciclo e não de um ano.
De acordo com o PNE, além das IES públicas, apenas as ICES, podem participar da elaboração e execução do Plano Estratégico em cada ente federado, com objetivo de cumprir a Meta 15. Com o presente Decreto, o qual não apresenta parâmetros claros sobre esse apoio financeiro às IES privadas, corre-se o risco de a Política Nacional de Formação seguir num caminho mercantilista.

Outro aspecto relevante é que nesse Decreto não consta o papel da CAPES e sua responsabilidade no apoio e fomento às ações de formação inicial e continuada dos profissionais docentes da Educação Básica como estabelecia o Decreto no 6.755, de 2009. A função, anteriormente atribuída à CAPES, volta-se para a alçada das secretarias do MEC que exerciam competências administrativas e técnicocientíficas. Contudo, não fica evidenciado se as ações de formação inicial e continuada podem passar a ser geridas pelo MEC, cabendo à CAPES apenas o fomento e apoio financeiro, com a colaboração do FNDE.

Em relação aos Fóruns Estaduais Permanentes de Apoio à Formação Docente é importante que sua atuação vá além do caráter meramente administrativo e burocrático, com efeito para o planejamento de curto, médio e longo prazo, que contribuam para superar os problemas da formação de professores, partindo do que estabelece o PNE: a formação em nível superior para todos os profissionais docentes da Educação Básica com garantia de qualidade. E, portanto, não abrindo possiblidades para abertura de portas de quaisquer instituições que buscam lucratividade na oferta de uma formação aligeirada e desarticulada da realidade educacional, banalizando, sobretudo, a formação dos profissionais docentes.

Diante da análise de conteúdo dos documentos referentes às políticas de profissionalização, em relação à formação docente, foi possível depreender que o PNE e as DCNs explicitam a intenção da criação de cursos e programas que buscam atender à formação de qualidade para todos os profissionais docentes, o que não fica claro no Decreto 8.752, por não apresentar a construção de uma política nacional de formação dos profissionais da educação como política de Estado, de caráter público e permanente. 


\section{À GUISA DE CONCLUSÃO}

Os documentos analisados possibilitaram apontamentos em direção ao atendimento a esses anseios, principalmente, nas metas e estratégias do PNE e no escopo das DCNs, propostas pensadas no coletivo, com diálogo e debate no campo das ideias e contexto político. Nesses documentos, a área da educação e da formação de professores vem tratando a questão da formação inicial e continuada intrinsicamente articulada à remuneração e carreira, condições de trabalho, - com destaque, à Resolução CNE/CP $\mathrm{n}=2 / 2015$, que ambiciona superar a histórica dicotomia entre esses polos - abrindo possibilidades para uma política de profissionalização que abrange a formação e a valorização dos professores enquanto profissionais docentes, criando condições também para organicidade do Sistema Nacional de Educação.

Por outro lado, o Decreto no 8.752/2016, que institui Política Nacional de Formação dos Profissionais da Educação Básica, embora dê continuidade ao que preconiza a planejamento educacional e as DCNs, por sua vez, registra alguns retrocessos em relação ao Decreto no $6.755 / 2009$, que afetam o campo para novas conquistas em relação às políticas de valorização, pois, além de não tratar destas questões de forma articulada, não enfatiza como prioridade, por exemplo, jornada de trabalho exclusiva em apenas uma escola, como garantia de melhores condições de trabalho. Muitos professores trabalham em diferentes escolas, acumulando uma carga horária exaustiva, as quais, não raras vezes, contribuem para um processo de desprofissionalização docente, haja vista, que o professor não consegue tempo viável para maior organicidade da sua rotina de trabalho, muito menos para processos de formação continuada.

Por isso, pensar a docência, enquanto profissão, é fundamental, que mais pessoas se sintam atraídas para essa carreira. Ser professor não é para qualquer pessoa e, por vezes, essa ideia errônea tem prevalecido aumentando a oferta de cursos que certificam de forma aligeirada (setor privado e de pouca qualidade), propagando a ideia de que qualquer um pode ser professor. No entanto, a docência é uma profissão que tem por base uma formação específica e ampla que perpassam conhecimentos científicos, didáticos e pedagógicos, bem como uma identidade muito própria. Um primeiro requisito para o caminho efetivo de profissionalização da docência deveria começar pela oferta de cursos de licenciatura, enquanto formação inicial, admitindo e validando somente cursos presenciais, no entanto, o cenário atual está num caminho contrário.

Para ser um profissional da educação é necessário e de grande importância que se viabilizem caminhos para a profissionalização. Quando ofertada precisa ser buscada por esse profissional que anseia pela sua profissionalidade. Mas, se em uma dessas partes não houver movimento o processo de profissionalização pode ficar comprometido. São dilemas que fazem parte da diacronia da temática em análise e que, infelizmente, no atual momento histórico, com o contexto econômico e político em crise, a conjuntura que se apresenta é de grandes incertezas e de perspectivas sombrias, as quais assombram, mais uma vez, a continuidade das políticas educacionais anunciadas, colocando em xeque o conjunto de metas propostas no Plano Nacional de Educação (2014-2024) para qualificar a educação brasileira.

Depois de quatro anos de longas discussões no Congresso Nacional, a aprovação do PNE, sem vetos, foi recebida com muito entusiasmo por toda sociedade. Porém, como já mencionado, sua sanção enquanto legislação não garantiu uma implementação imediata, sem questionamentos ou dificuldades. O cenário político, no primeiro ano do Plano, foi marcado pela acirrada disputa de eleição presidencial, seguido de trocas em ministérios e conflitos institucionais, o que dificultou seu andamento. (BRITTO, 2017).

Não obstante, consumado o golpe de Estado, o impeachment da Presidenta Dilma, em agosto de 2016, sucederam novas trocas de administração, com significativa reorientação das prioridades educacionais na seara educacional, com diversas medidas antipopulares, com maior destaque, certamente, a adoção de rigoroso regime de austeridade fiscal, que foi empreendida com a aprovação da Emenda Constitucional no $95^{19}$, de 15 de dezembro de 2016 - também reconhecida como a "PEC do teto dos gastos públicos", que teve origem na PEC no 241 na Câmara Federal e na PEC no 55 no Senado Federal - a qual determina um Novo Regime Fiscal, pois estabelece um limite para as despesas primárias

\footnotetext{
${ }^{19}$ As emendas constitucionais são uma ferramenta de importante relevância política-administrativa, pois alteram diretamente a Constituição Federal, e os direitos dela provenientes.
} 
de um governo, por duas décadas ${ }^{20}$, dentre as quais está a educação. Como afirma Mancebo (2016, p. 645) "na prática, trata-se de constitucionalizar a política de "austeridade", tornando-a obrigatória a qualquer governo, visando, com isso, a ampliar superávits para o pagamento de juros da dívida pública, em prejuízo dos serviços públicos." Nessa direção, "o choque entre interesses e demandas sociais e, principalmente, entre políticas já consolidadas é, de certo modo, previsível em todos os níveis de nosso sistema federativo, uma vez que cada um possui responsabilidades." (CALDERAN, 2016, p. 5).

Além do campo educacional, a saúde, a previdência, ciência e tecnologia, serão sacrificadas também outras áreas, como: cultura, justiça, assistência social e segurança, projetos habitacionais, de infraestrutura, de transportes e tudo o mais que depende do setor público, seja em nível federal, estadual ou municipal. (HELENE, 2016). Em relação à educação o autor explana que

Os investimentos diretos
em educação serão
reduzidos em cerca de
$40 \%$ Os recursos,
atualmente de pouco mais
que $5 \%$ do PIB, cairão para
cerca de $3 \%$ do PIB até
2036 , um padrão que nos
colocará, quase em
meados do século 21 em
uma situação como aquela
do final da década de 1990,
um retrocesso totalmente
inaceitável e que nos
recolocará entre os países
mais atrasados de todo o
mundo no que diz respeito
à capacidade de superar
atrasos educacionais.
(HELENE, 2016, p. 1).

O PNE vislumbrou novos caminhos, alimentando a esperança para efetivar uma educação pública de qualidade. No entanto, os aportes para efetivá-la não foram confirmados e, o retrocesso político do momento, compromete, perigosamente, muitas conquistas sociais, num percurso de desmonte das políticas sociais e inviabilização de mais um planejamento educacional. O parlamento que sancionou o PNE foi o mesmo que o destruiu com a aprovação da

\footnotetext{
${ }^{20}$ Nesses 20 anos, que se estenderão até 2036, abrangerão, além do PNE 2014-2024, também o próximo PNE que compreenderá o período de 2025 a 2035.
}

EC 95. Podemos inferir que o congelamento dos gastos primários, implicam fortemente no desenvolvimento da Meta 20 do PNE e, por consequência, nas demais metas, pois resultará numa árdua estagnação de um construto histórico e de evolução educacional que estava em desenvolvimento. 0 objetivo da Meta 20 em ampliar até 2024 o investimento em educação para $10 \%$ perde o sentido. Sabemos que ao invés de corte de gastos a educação precisa de maiores investimentos, com políticas planejadas e estruturadas a fim de qualificar a educação, com maior atenção à formação inicial e continuada, de valorização docente e infraestrutura adequada.

Congruente ao supracitado concretiza-se o fato de as políticas educacionais tomarem diversas facetas, dentro das arenas políticas, manifestando-se, dessa forma, como forte objeto de disputa de poder, na qual a educação passa a ser um objeto de troca, assumindo caráter de mercadoria. Educação é direito, não mercadoria, tem que ser para todos. As medidas tomadas pelo governo nos últimos tempos, em que pese o anúncio dos investimentos na educação, estão na contramão do proclamado, no planejamento educacional viabilizados por ações de ordem capitalista.

\section{REFERÊNCIAS}

BARDIN, L. Análise de Conteúdo. Lisboa: Edições 70, 1977.

BRASIL. CONAE 2010. Conferência Nacional de Educação. Construindo o Sistema Nacional Articulado de Educação: o Plano Nacional de Educação, diretrizes e estratégias. Documento Final. Brasília, DF: MEC, 2010. Disponível em: <http://pne.mec.gov.br/images/pdf/CONAE2 010_doc_final.pdf>. Acesso em: 03. jan. 2016.

BRASIL. Constituição (1988). Constituição da República Federativa do Brasil. Brasília, DF: Senado, $1988 . \quad$ Disponível em: <www.planalto.gov.br/ccivil_03/constituicao/co nstitui\%C3\%A7ao.htm.> Acesso em 04. jan. 2016.

BRASIL. Decreto no 8.752, de 9 de maio de 2016. Dispõe sobre a Política Nacional de Formação dos Profissionais da Educação Básica. Brasília, 2016. Disponível em: http://www.planalto.gov.br/ccivil_03/_Ato20152018/2016/Decreto/D8752.htm. Acesso em: 01 jun. 2016. 
BRASIL. Lei n. 13.005/14, de 25 de junho de 2014. Aprova o Plano Nacional de Educação - PNE e dá outras providências. Diário Oficial da União, Brasília, DF, 26 jun. 2014, p. 1, Edição Extra. Disponível

em: <http://www.planalto.gov.br/ccivil_03/_ato20 112014/2014/lei/l13005.htm>. Acesso em 30. dez. 2015.

BRASIL. Lei n. 9.394/96, de 20 de dezembro de 1996. Estabelece as diretrizes e bases da educação nacional. Diário Oficial da União, Brasília, DF, 23 dez. 1996. p. 27894.

BRASIL. Planejando a próxima década: conhecendo as 20 metas do Plano Nacional de Educação. Brasília: Ministério da Educação/ Secretaria de Articulação com os Sistemas de Ensino (MEC/ SASE), 2014. Disponível em: <http://pne.mec.gov.br/images/pdf/pne_conhece ndo_20_metas.pdf>. Acesso em 04. jan. 2016.

BRASIL. Plano Nacional de Educação PNE 20142024: linha de base. Brasília: Presidência da República Federativa do Brasil/ Ministério da Educação - MEC/ Secretaria Executiva/ Instituto Nacional de Estudos e Pesquisas Educacionais Anísio Teixeira - Inep/ Diretoria de Estudos Educacionais - Dired, 2015. Disponível em: < http://www.deolhonosplanos.org.br/wpcontent/u ploads/2015/10/Plano_Nacional_de_Educacao_L inha_De_Base.pdf>. Acesso em 30. dez. 2015.

BRASIL. Resolução no 2, de 10 de julho de 2015. Define as Diretrizes Curriculares Nacionais para a formação Inicial em nível superior e para a formação continuada dos profissionais da educação básica. Diário Oficial da União, Brasília, DF, 02 de jul. de 2015. Seção 1, p. 8-12.

BRITTO, T. F. de. A meta 15 do PNE: significados, implicações e agenda da formação dos profissionais da educação. In: GOMES, Ana Valeska Amaral (org.). Plano Nacional de Educação: olhares sobre o andamento das metas. Brasília : Câmara dos Deputados, Edições Câmara, 2017.

CALDERAN, A. M.; CALDERAN, A. Implementação da Emenda Constitucional 95/2016: reflexões sobre suas possíveis implicações nas políticas educacionais da infância. Disponível em: $<$ www3.fe.usp.br/secoes/inst/novo/agenda_even
tos/inscricoes/PDF/58844.doc>. Acesso em: 14 de out. de 2017.

DIAS, R.; MATOS, F. O conceito de política pública. In: DIAS, Reinaldo; MATOS, Fernando. Políticas públicas: princípios, propósitos e processos. São Paulo: Atlas, 2012. p. 1-19.

DOURADO, L. F. Diretrizes curriculares nacionais para a formação inicial e continuada dos profissionais do magistério da educação básica: concepções e desafios. Educação \& Sociedade, Campinas, v. 36, n. 131, p. 299-324, abr-jun. 2015. DOI: $\quad$ 10.1590/ES0101-73302015151909. Disponível em: http://www.scielo.br/scielo.php?script=sci_arttex t\&pid=S0101-73302015000200299. Acesso em: 15 set. 2015.

FREITAS, H. C. L. de. PNE e formação de professores: contradições e desafios. Retratos da Escola, Brasília, v. 8, n. 15, p. 427-446, jul./dez. 2014.

GENTILI, P. A falsificação do consenso: simulacro e imposição na reforma educacional do neoliberalismo. Petrópolis, Rio de Janeiro: Vozes, 1998.

GIL, A. C. Como elaborar projetos de pesquisa. São Paulo: Atlas, 2002.

HELENE, O. PEC 241 torna inconstitucional o desenvolvimento social e cultural., 2017. Disponivel em: <http://www.sintunesp.org.br/Artigo\%200tavian o\%20-

\%20PEC\%20241\%20torna\%20inconstitucional\%20 ०\%20desenvolvimento\%20social\%20e\%20cultural .pdf>. Acesso em: 07 de out. de 2017.

HONÓRIO; M. G.; et al. As novas diretrizes curriculares nacionais para a formação inicial e continuada de professores da Educação Básica: entre recorrências e novas inquietações. Revista Ibero-Americana de Estudos em Educação, v.12, n. 3, p. 1736-1755, jul./set. 2017. DOI: 10.21723/riaee.v12.n.3.2017.8532. Disponível em: https://periodicos.fclar.unesp.br/iberoamericana/ article/view/8532/6759. Acesso em: 16 out. 2017.

IMBERNÓN, F. Formação permanente do professorado : novas tendências. São Paulo: Cortez, 2009. 
LIBÂNEO, J. C. Adeus professor, adeus professora?: novas exigências educativas e profissão docente. São Paulo: Cortez, 1998.

LIMA, A. B. de. Estado e controle social no Brasil. Uberlândia: FAPEMIG, 2009.

LUCE, M. B. Formação de professores: a política e as diretrizes curriculares. Em Aberto, Brasília, v. 30 , n. 98, p. 185-200, jan./abr. 2017. DOI: 10.24109/2176-6673.emaberto.30i98.3187.

Disponível em: http://emaberto.inep.gov.br/index.php/emaberto /article/view/3187. Acesso em: 20 ago. 2017.

MALANCHEN, J.; VIEIRA, S. da R. A política brasileira de formação de professores: repercussões sobre o trabalho docente. In: SEMINÁRIO DA REDEESTRADO, 6., Rio de Janeiro. Anais... Rio de Janeiro: UERJ, 2006.

MANCEBO, D. Expansão da educação superior: balanço, perspectivas e desafios. (Editorial). Revista Brasileira de Política e Administração da Educação (RBPAE). Goiânia: ANPAE, 2016. v. 32. n. 3. set./dez. 2016.

NÓVOA, A. Formação de professores e profissão docente. In: NÓVOA, A. (Coord.). Os professores e sua formação. Lisboa: Dom Quixote, 1992.

OBSERVATÓRIO DO PNE. 2016. Disponível em: http://www.observatoriodopne.org.br/. Acesso em 5 jan. 2016.

OLIVEIRA, D. A. Das políticas de governo à política de estado: reflexões sobre a atual agenda educacional brasileira. Educação e Sociedade, Campinas, v. 32 , n. 115 , p. 323-337, abr.-jun. 2011. DOI: 10.1590/S0101-73302011000200005. Disponível em: http://www.scielo.br/scielo.php?script=sci_arttex t\&pid=S0101-

73302011000200005\&lng=pt\&tlng=pt. Acesso em: 15 jan. 2016.

PEREIRA, J. D. A formação acadêmico-profissional: compartilhando responsabilidades entre universidades e escolas. In: EGGERT, Egla. et al. Trajetória e processos de ensinar e aprender: didática e formação de professores. Porto Alegre: PUCRS, 2008, p. 253-266.
PEREIRA, J. E. D. O Plano Nacional de Educação e as questões sobre a valorização e formação do profissional da educação. Interfaces da Educação, Paranaíba, v. 4, n. 10, p. 78-91, 2013.

RIBEIRO, L. de M.; SILVA, C. M. As políticas de formação de professores e o Plano Nacional de Educação no contexto da reestruturação capitalista no Brasil. Educação e Contemporaneidade, Salvador, v. 21, n. 37, p. 5362, jan./jun. 2012.

SACRISTÁN, J. G. ; GÓMEZ, A. I. Compreender e transformar o ensino. 4. ed. Porto Alegre: Artmed, 1993.

SARAIVA, C. Novo PNE: uma sistematização da contra reforma do ensino superior. CSP- Conlutas - Central Sindical e Popular. 03/05/2011. Disponível em: <http://www.pstu.org.br/node/16328 >. Acesso em: 05 jan. 2016.

SCHEIBE, L. O Processo de Formação Docente no Brasil. Site URI, Frederico Westphalen, 27 abr. 2016. P. 1-2. Entrevista.

SHIROMA, E. O. ; MORAES, M. C. M. de ; EVANGELISTA, O. Política Educacional. 4. ed. Rio de Janeiro: Lamparina, 2011.

VALENTE, L. de F.; COSTA, M. S. P. F. M.; SANTOS, F. H. dos. Nas trilhas do planejamento educacional e seus contornos nas políticas de educação no Brasil. RBPAE, v. 32 , n. 1, p. 025-045, jan./abr. 2016.

Recebido para avaliação: 15/10/2018

Revisado em: 22/11/2018

Aceite Final: 25/11/2018 